\title{
Efetividade do Aumento da Área de Reserva Legal por Meio de Instrumento Legal na Taxa de Desmatamento da Amazônia Brasileira
}

\author{
Alexandre Nascimento de Almeida ${ }^{1}$, Humberto Angelo ${ }^{2}$, \\ João Carlos Garzel Leodoro da Silva ${ }^{3}$, Philipe Ricardo Casemiro Soares ${ }^{3}$, \\ Maria Raquel Kanieski ${ }^{3}$ \\ ${ }^{1}$ Faculdade UnB de Planaltina - FUP, Universidade de Brasília - UnB, Brasília/DF, Brasil \\ ${ }^{2}$ Engenharia Florestal, Universidade de Brasília - UnB, Brasília/DF, Brasil \\ ${ }^{3}$ Departamento de Economia Rural e Extensão, Universidade Federal do Paraná - UFPR, Curitiba/PR, Brasil
}

\section{RESUMO}

Sob o impacto da divulgação do índice de desmatamento recorde em 1995, editou-se a Medida Provisória (MP) 1.511/96, que, dentre outras modificações, aumentou a Reserva Legal na Amazônia de 50 para $80 \%$, na expectativa de conter o desmatamento. O objetivo deste estudo foi avaliar a efetividade dessa medida provisória como ferramenta para auxiliar na conservação do bioma. Para tanto, foram comparadas as taxas de desmatamento nos períodos anterior e posterior à edição da MP, por meio da análise de regressão sobre a variável dicotômica. Os resultados indicaram que não existe diferença significativa entre a área desmatada antes e depois da MP, não sendo possível afirmar que a maior restrição da legislação levou à redução do desmatamento.

Palavras-chave: Código Florestal, conservação, economia e política florestal, Floresta Amazônica.

\section{Evaluation of Increase Effectiveness in a Legal Reserve Area} Through Legal Instrument in the Brazilian Amazon Deforestation Rate

\begin{abstract}
Under the impact caused by the disclosure of the record deforestation rate in 1995, the Brazilian Federal Government issued a Provisional Measure (PM) which, among other changes, increased the size of legal reserves in the Amazon from 50 to $80 \%$ hoping to reduce deforestation. In this study, we aimed to evaluate the effectiveness of this provisional measure as a tool to assist in the conservation of this biome. To this end, we compared deforestation rates before and after the PM by dummy variable regression analysis. Results indicated that there is no significant difference between the deforested area before and after the PM; we could not demonstrate that increased restriction in legislation has led to deforestation reduction.
\end{abstract}

Keywords: forest code, conservation, economics and policy forest, Amazon. 


\section{INTRODUÇÃO}

Atualmente, uma grande discussão no Brasil refere-se à iminente flexibilização do Código Florestal em função da aprovação do projeto de Lei $\mathrm{n}^{\circ} 30$ de 2011, proposto pelo Deputado Federal Aldo Rebelo.

Entre as modificações iniciais mais controversas, destacaram-se:

- Isenção de Reserva Legal em pequenas propriedades;

- Redução das faixas de mata ciliar ao longo dos rios de largura inferior a 10 metros e ao redor de nascentes;

- Legalização das áreas desmatadas em áreas consolidadas (área de imóvel rural com ocupação preexistente antes de 22 de julho de 2008);

- Concessão aos Estados da prerrogativa de legislar sobre as áreas de preservação.

Embora tenha sido aprovado com ampla maioria na Câmara dos Deputados, o projeto de lei foi bastante modificado no Senado e tem sofrido muitas críticas de ambientalistas, de cientistas e da sociedade civil. Em geral, as críticas à flexibilização do Código Florestal podem ser resumidas em uma única preocupação: as modificações poderão levar ao aumento do desmatamento, conforme demonstrado por Sparovek et al. (2011).

Por outro lado, uma legislação ambiental mais restritiva não garante, necessariamente, a redução do desmatamento. Caso esteja fora da realidade dos agentes que efetuam os desmatamentos e o Estado não possua aparato eficiente para fiscalização e implantação, a legislação passa a servir apenas para esconder a realidade, tornando-se negativa e contraproducente. Duas evidências na literatura científica da incapacidade desse tipo de estratégia para atingir seus objetivos são os trabalhos de Zhang et al. (2000) e Oliveira \& Bacha (2003).

Não é a primeira e, provavelmente, não será a última vez que o Código Florestal dividirá a opinião dos especialistas; fato similar ocorreu em 1995, com a edição da MP 1.511/96.

Conforme Prioste et al. (2009), sob o impacto da divulgação do índice de desmatamento de quase 30 mil km² em 1995 (recorde histórico), a MP 1.511/96 inaugurou a edição de uma série de medidas provisórias que alteraram de forma significativa as disposições do Código Florestal sobre a Reserva Legal. Essa MP aumentou a Reserva Legal na Amazônia de 50 para $80 \%$ da propriedade e proibiu a conversão de áreas florestais em agrícolas nos estabelecimentos rurais que possuíssem fração já desmatada, abandonada ou subutilizada, de acordo com a capacidade de suporte.

O objetivo deste estudo foi verificar o efeito no desmatamento da Medida Provisória 1.511 de 1996, que aumentou a Reserva Legal na Amazônia de 50 para $80 \%$, como base para verificar o efeito de medidas restritivas para conter o desmatamento na Amazônia Legal.

\section{MATERIAL E MÉTODOS}

O método utilizado foi o dos Mínimos Quadrados Ordinários - MQO, mensurando o efeito da mudança da legislação (MP 1.511/96) no desmatamento por meio da utilização de uma variável dicotômica (dummy), conforme a Equação 1.

$D_{t}=\alpha_{1}+\alpha_{2} M P_{t}+\varepsilon_{t}$

em que: $\mathrm{D}_{\mathrm{t}}=$ taxa de desmatamento na Amazônia Legal $\left(\mathrm{km}^{2} / \mathrm{ano}\right) ; \mathrm{MP}_{\mathrm{t}}=0$ e $\mathrm{MP}_{\mathrm{t}}=1$, antes e depois da edição da MP 1.511/96, respectivamente; $\varepsilon_{\mathrm{t}}=$ erro estocástico.

O período antes da MP 1.511/96 compreendeu os anos de 1988 até 1996 e os anos de 1997 a 2011 corresponderam aos dados após a edição da referida MP (Figura 1). Os dados referentes à taxa de desmatamento na Amazônia Legal podem ser

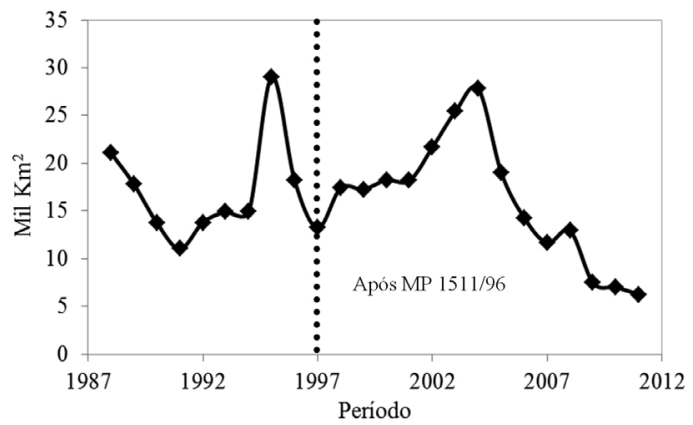

Figura 1. Evolução do desmatamento da Amazônia entre o período de 1988 e 2011. Fonte: INPE (2012).

Figure 1. Evolution of Amazon deforestation between the period 1988 to 2011. Source: INPE (2012). 
obtidos no INPE - Instituto Nacional de Pesquisas Espaciais (2012).

As hipóteses foram testadas pelo teste $t$ unicaudal, em que:

- $\mathrm{H}_{0}$ : não há diferença entre a área desmatada antes e depois da MP 1.511/96 ( $\left.\alpha_{1}=0\right)$;

- $\mathrm{H}_{1}$ : área desmatada após MP 1.511/96 é menor $\left(a_{1}<0\right)$.

No caso do teste $t$ rejeitar $\mathrm{H}_{0}$, outras hipóteses testadas para validar $H_{1}$ referem-se à avaliação de multicolineariedade, heteroscedasticidade e autocorrelação. Caso não seja possível rejeitar $\mathrm{H}_{0}$, os testes econométricos citados são desnecessários (Gujarati, 2000).

\section{RESULTADOS E DISCUSSÃO}

Para testar o efeito da MP analisada, utilizou-se a Equação 2.

$\hat{D}_{t}=17.153-1.298 M P_{t}$

Teste $t(8,56)(-0,51)$

$\mathrm{n}=24 \quad \mathrm{R}^{2}=0,01 \quad \mathrm{~F}=0,26 \quad d=0,71$

Como $a_{2}$ não é significativo, não é possível rejeitar $\mathrm{H}_{0}$ com $5 \%$ de significância; portanto, não se pode afirmar que a taxa de desmatamento diminuiu após a MP 1.511 de 1996.

O valor da constante $\left(\alpha_{1}\right)$ de $17.153 \mathrm{~km}^{2}$ referese à taxa média de desmatamento antes da MP, pouco superior à média de $15.855 \mathrm{~km}^{2}\left(\alpha_{1}\right.$ menos $\left.\alpha_{2}\right)$ registrada após a sua edição.

Além da questão legal, muitas outras variáveis afetam o desmatamento na Amazônia, como, por exemplo, os aspectos econômicos ligados, principalmente, à agropecuária e à indústria madeireira (Angelo \& Sá, 2007). Embora a análise não leve em consideração o efeito de outras variáveis, diante das mudanças tão expressivas da MP 1.511/96, espera-se a redução do desmatamento, o que torna a análise adequada.

Um dos motivos da não redução do desmatamento após a MP 1.511/96 foi a incapacidade de tornar a legislação aplicável, passível de ser cumprida pelos produtores rurais e fiscalizada pelos órgãos ambientais.
As conclusões de Sparovek et al. (2011) corroboram os resultados encontrados. Os autores apontam que talvez o tema mais negligenciado no debate tenha sido o fato de o Código Florestal não ter produzido os efeitos desejados, e de como as alterações, adaptações ou regulamentações podem chegar a esse resultado no futuro, mesmo que o efeito desejado seja outro (menos restrito).

Nesse contexto, destaca-se a reflexão de Aicher (2004). Segundo o autor, a política florestal não se limita às leis ou aos decretos de um Estado, pois também é preciso incluir, por exemplo, os conflitos e processos sociais que motivam as ações de pessoas, de uma sociedade ou de um governo, e que podem causar mudanças na maneira como as florestas são usadas ou manejadas.

Com frequência, ouvem-se queixas de que as leis são boas, porém não são aplicadas. No sentido tradicional, isso seria simplesmente um problema da fiscalização e do poder do Estado em implementar seus objetivos. A solução seria buscada nas tentativas estatais de melhorar a eficiência da administração. Porém, não tem sentido fiscalizar cada pessoa que se aproxima de uma floresta, nem seria economicamente eficiente.

Além disso, uma sociedade que se baseia somente em controle e medo não é 'convidativa' nem sustentável, como mostram os colapsos de regimes totalitários. Não há preocupações em ver se estes objetivos são aceitos pela sociedade, se eles têm legitimidade, se têm sentido para os usuários, como são institucionalizados e integrados nas práticas, etc.

No entanto, esses aspectos são essenciais quando se quer entender e, possivelmente, mudar ações de seres humanos ou coletivos. Por isso, é necessário ampliar o conceito de política florestal, ou seja, adaptá-lo às mudanças da percepção da sociedade em geral. Não é suficiente se ocupar só das regras da produção ou da exploração de madeira, mas sim incluir outros aspectos ligados a conflitos sobre florestas, sobre seu uso e sobre formas socialmente aceitas de tratamento desses conflitos.

Corroborando o argumento de Aicher (2004) e Rocha \& Silva (2009) destacaram a necessidade da ampla atuação do Estado para o estabelecimento de uma política florestal eficiente nas seguintes funções: 
1) realizar o macroplanejamento da proteção e da utilização dos recursos florestais; 2) administrar as áreas florestais públicas; 3) prestar assistência técnica e extensão florestal; 4) promover o fomento da atividade florestal; 5) realizar a pesquisa florestal, e 6) monitorar, controlar e fiscalizar a cobertura dos proprietários privados.

Conforme esses autores, em geral, o cumprimento das funções destacadas no Brasil é precário, identificando como principais gargalos aquelas relacionadas ao monitoramento, ao controle e à fiscalização da cobertura dos proprietários privados, e à prestação de assistência técnica e extensão florestal; note-se que esses aspectos são preponderantes para implantação e eficiência da MP 1.511/96.

Hirakuri (2003) identificou o baixo cumprimento da legislação florestal pelos madeireiros na Amazônia e, comparando com a situação oposta presente na Finlândia, apontou as principais dificuldades em relação ao cumprimento dessa lei no Brasil: 1) excesso de burocracia e complicação para adquirir permissões de manejo; 2) ineficiência da fiscalização e do controle florestal; 3) ineficiência do poder judiciário na aplicação de multas aos infratores; 4) desconhecimento e baixa confiança em relação à legislação pelos madeireiros; 5) falta de incentivos financeiros ao manejo florestal; 6) ausência de extensão florestal; 7) incentivos econômicos para atividades opostas ao manejo sustentável, e 8) falta de cultura florestal.

Embora a MP 1.511/96, no seu artigo terceiro, até hoje vigente, permita o manejo florestal sustentável nas áreas de Reserva Legal, possibilitando, teoricamente, ao produtor rural aferir renda da exploração florestal, é necessário e justificado o suporte do Estado para o desenvolvimento da atividade, tendo em vista sua baixa atratividade e a geração de benefícios ambientais públicos sem uma contrapartida pecuniária do produtor rural (Timofeiczyk Junior et al., 2008; Fasiaben et al., 2011).

Destaca-se um conjunto de intenções recentes na discussão do projeto de Lei $n^{\circ} 30$ de 2011, visando a desenvolver e ampliar o pagamento dos serviços ambientais. Certamente, esse é o principal ponto de convergência entre ambientalistas e ruralistas; porém, diante da alta carga tributária, da corrupção e dos recursos escassos em áreas, como saúde e educação no Brasil, dificilmente a sociedade civil aceitaria a criação de algum tributo ou o maior direcionamento de recursos para a causa ambiental.

Embora conceitualmente diferente, na prática, a Reserva Legal tem tido o mesmo papel das Áreas de Preservação Permanente (APPs), em função do limitado uso sustentável dos recursos naturais nas reservas legais. A diferença básica entre Reserva Legal e APP é que a primeira permite uma grande subjetividade na definição da área de sua alocação, dificultando ainda mais a sua aplicação, na visão de Delalibera et al. (2008), e contribuindo para explicar os resultados encontrados.

Provavelmente, o principal efeito da MP 1.511/96 tenha sido acirrar o debate entre ruralistas e ambientalistas, e trazer insegurança jurídica no campo. Após a edição da referida MP, o que se verificou foi uma série de medidas de flexibilização para o seu cumprimento, como, por exemplo, a MP 1.736-31/98, que instituiu as formas de compensação e recomposição da Reserva Legal, e admitiram a soma da Área de Preservação Permanente no cômputo do porcentual da área de Reserva Legal (Prioste et al., 2009). No entanto, essas medidas tiveram poucos resultados em razão de restrições decorrentes de sua definição e regulamentação (Sparovek et al., 2011), culminando no projeto de Lei $\mathrm{n}^{\circ} 30$ de 2011, na direção de uma maior flexibilização ambiental do Código Florestal.

Siqueira \& Nogueira (2003), analisando a MP $1.511 / 96$, concluíram que a estratégia do governo brasileiro de impor de forma severa a conservação de terras cobertas com florestas por meios alheios ao mercado pode resultar, ao contrário do que se imagina, em custos sociais elevados, além de impor uma perda considerável na liberdade dos proprietários de terra, redundando em consequências diferentes das inicialmente almejadas.

$\mathrm{Na}$ mesma linha, Schneider et al. (2005) apresentaram as diversas alterações sofridas pelo Código Florestal e reconheceram a dificuldade dos legisladores em conciliar os interesses dos diversos atores envolvidos no assunto, expondo a 
inabilidade da aplicação da legislação. Segundo os autores, enquanto as discussões sobre a Reserva Legal continuam no Congresso, nas assembleias e nas câmaras, sem que se chegue a um consenso sobre qual vai ser o seu destino, a conservação dos remanescentes de vegetação nativa nas propriedades continuará a depender, principalmente, da decisão dos produtores rurais em proteger essas áreas ou não.

Ainda segundo os autores, após três décadas de implantação, o padrão convencional de agricultura no Brasil tem-se mostrado insustentável, não só pelo aumento da pobreza e pelo aprofundamento das desigualdades, mas também pelos impactos ambientais negativos causados pelo desmatamento continuado, pela redução dos padrões de diversidade preexistentes, pela intensa degradação dos solos agrícolas e pela contaminação química dos recursos naturais, entre tantos outros impactos. Ou seja, diante da falta de um consenso mínimo entre ambientalistas e ruralistas, no final os maiores perdedores têm sido o meio ambiente e a sociedade.

\section{CONCLUSÕES}

Não é possível afirmar que uma legislação ambientalmente mais restritiva (MP 1.511/96) tenha garantido menor taxa de desmatamento da Amazônia brasileira. Com isso, torna-se fundamental a observação dos princípios da razoabilidade e da proporcionalidade na sua elaboração, não devendo se esquecer de que o desenvolvimento, para ser sustentável, deve respeitar, além dos pilares ambiental e social, o pilar econômico. Ou então, deve respeitar, além do pilar econômico, o ambiental e o social.

Com certeza, as modificações bruscas na legislação, que desrespeitem condições tecnológicas e culturais iniciais, e não possuam aparato suficiente para fiscalização e implantação, somadas a um poder judiciário lento e ineficiente, não contribuem para o desenvolvimento sustentável da Região Amazônica.

\section{STATUS DA SUBMISSÃO}

Recebido: $20 / 08 / 2012$

Aceito: 27/04/2013

Publicado: 30/06/2013

\section{AUTOR(ES) PARA CORRESPONDÊNCIA}

\section{Alexandre Nascimento de Almeida}

Faculdade UnB de Planaltina - FUP, Universidade de Brasília - UnB, Área Universitária 01, Vila Nossa Senhora de Fátima, CEP: 73.345-010, Planaltina, DF, Brasil e-mail: alexalmeida@unb.br

\section{REFERÊNCIAS}

Aicher C. A política florestal europeia: um sonho ou uma realidade? Ciência Florestal 2004; 14(2): 177-188.

Angelo H, Sá SPP. O desflorestamento na Amazônia Brasileira. Ciência Florestal 2007; 17(3): 217-227.

Delalibera HC, Weirich PH No, Lopes ARC, Rocha CH. Alocação de reserva legal em propriedades rurais: do cartesiano ao holístico. Revista Brasileira de Engenharia Agrícola e Ambiental 2008; 12(3): 286-292. http://dx.doi. org/10.1590/S1415-43662008000300010

Fasiaben MCR, Romeiro AR, Peres FC, Maia AG. Impacto econômico da reserva legal sobre diferentes tipos de unidades de produção agropecuária. Revista de Economia e Sociologia Rural 2011; 49(4): 1051-1096. http://dx.doi.org/10.1590/S0103-20032011000400010

Gujarati DN. Econometria básica. 3. ed. São Paulo: Makron Books; 2000.

Hirakuri SR. Can law save the forest? Lessons from Finland and Brazil. 2003. Center for International Forest Research - CIFOR. [cited 2012 jun. 28]. Available from: http://www.cifor.org/publications/pdf_files/Books/ Law.pdf.

Instituto Nacional de Pesquisas Espaciais - INPE. [cited 2012 jun. 03]. Available from: http://www.inpe. br/.

Oliveira SJM, Bacha CJC. Avaliação do Cumprimento da Reserva Legal no Brasil. Revista de Economia e Agronegócio 2003; 1(2): 177-203.

Prioste FGV, Avanci J, Pacher L, Vieira J. Mudanças na legislação ambiental e os reflexos na agricultura familiar camponesa e povos e comunidades tradicionais: subsídios técnicos e políticos para o debate. 2009. [cited 2012 jun. 03]. Available from: http://www.boelllatinoamerica.org/.../Estudo_sobre_Codigo_Florestall. pdf.

Rocha JDS, Silva JA. As funções de estado na área florestal: suas interrelações com a constituição federal e com o programa nacional de florestas. Floresta 2009; 39(2): 253-271.

Siqueira CFA, Nogueira JM. O Novo Código Florestal e A Reserva Legal: do preservacionismo desumano 
ao conservacionismo politicamente correto. 2003. [cited 2012 jun. 28]. Available from: http://www.sober. org.br/palestra/12/08O387.pdf.

Schneider AV, Rochadelli R, Bonilha RM. Impacto socioeconômico decorrente da implementação da reserva florestal legal: um estudo de caso. Floresta 2005; 35(3): 495-499.

Sparovek G, Barretto A, Klug I, Papp L, Lino J. A revisão do Código Florestal brasileiro. Novos
Estudos 2011; 89: 111-135. http://dx.doi.org/10.1590/ S0101-33002011000100007

Timofeiczyk Junior R, Da Silva VSM, Berger R, Sousa RATM. Rentabilidade econômica do manejo de baixo impacto em florestas tropicais: um estudo de caso. Floresta 2008; 38(4): 711-725.

Zhang P, Shao G, Zhao G, Master DCL, Parker GR, Dunning JB Jr, Li Q. China's Forest Policy for the 21st Century. Science Magazine 2000; 288(5474): 2135-2136. 